\title{
FEATURES OF THE RELATIONSHIP OF JUDGES AND CHAIRMAN OF COURTS IN THE RUSSIAN FEDERATION
}

Elvira M. Gubaidullina ${ }^{1}$

Artur A. Gubaidullin ${ }^{2}$

\begin{abstract}
The issue of ensuring the real independence of the court is a multidimensional one, and perhaps this is really an area, in which it is impossible to solve all problems at once, by adopting one single (albeit very thoughtful) law. This is an area in which translational movement is a necessary component of success. In any case, it is difficult to argue with the fact that the quality of the judicial system at the moment and its gradual development in the future is an important milestone in the development of the state and society [1].The purpose of this work is as follows: consideration of the current legislative provisions governing the legal status of the presiding judge, identification of interaction areas between ordinary judges and presiding judges, analysis of proposed changes to the legislation governing the activities of court leaders and assessment of the possible consequences of the adoption of
\end{abstract}

these provisions of the law. Based on the review results, it is concluded that the most optimal way to ensure the independence of the judiciary in the Russian Federation is the real irremovability of judges when they are appointed without limiting the term of office, provided that a high-quality, effective and transparent system for evaluating their work is developed, with a clear establishment of the level and procedure for bringing to justice, up to the possibility of deprivation of the corresponding position or status.

Keywords: judicial system of the Russian Federation, independence of the court, presiding judge, judge, irremovability.

\section{Introduction \\ Summarizing the current legislation governing the independence of the court and the judicial system and}


some clarifications of the Constitutional Court of the Russian Federation, the following most general provision can be deduced:

\section{A) on the justice system in the}

Russian Federation: justice in the Russian Federation is carried out only by a court that independently exercises judicial power in the country at the expense of the federal budget, regardless of any will, ensuring the implementation of the principle of power separation and guided by the goal of ensuring complete and independent justice in accordance with the federal law.

B) on judges: judges are independent, irremovable, inviolable, and obey only the Constitution of the Russian Federation and the federal law as the representatives of the judiciary.

C) on activities for the administration of justice: in their activities, judges are not accountable to anyone, independent of attachments and extraneous influences, cases are considered in the conditions that exclude extraneous influence on them, under the threat of bringing those responsible to justice under the laws of the Russian Federation.
D) on guarantees of

independence: independence is ensured by measures of legal protection, material and social security, safety provision, presence of a system of judicial community bodies and provision of its activities, procedure for administering justice stipulated by law, special requirements for candidates in their selection and appointment, establishment of a procedure for suspending and terminating the powers of a judge, and right of a judge to resign. Everything looks quite optimistic according to the law, but in reality it turns out that the real picture is far from rosy. Let us review how these provisions are refracted in the relationship between the presiding judges and "ordinary" judges.

\section{Methods}

The following methods of scientific knowledge were used as the main ones in the work:

1) Analysis. The problematic aspects of the relationship between the presiding judges and ordinary judges are established, taking into account the provisions of the current legislation, the problem blocks of the study are 
identified. At the same time, the statements of current practitioners of the judicial system and the public position openly expressed in the media were also analyzed.

2) Forecasting was used to track whether the introduced or proposed changes to the current legislation are able to really resolve the shortcomings identified in the study subject.

3) Generalization. A generalization of the entire set of problematic aspects of the relationship between the presiding judges and ordinary judges was carried out and general proposals were made to resolve these shortcomings.

4) Systemic research method. The specific features of the relationship between the presiding judges and judges within the specific blocks of the study of their relations are identified: appointment of a judge to the respective court, distribution of cases between judges, disciplinary responsibility of judges, career development of judges, promotion of judges, organizational issues.

5) Methods of deduction and induction. Using these methods of scientific knowledge, specific findings of the study were indicated.

\section{Results and discussion}

Given the stated research topic, we will identify the areas of direct interaction between presiding judges and "ordinary" judges, in which there is a threat of appropriate pressure:

1) Appointment of a judge of the relevant court. The presiding judge is the person, who represents the qualification collegium of judges with a profile of a pretending judge or a deputy presiding judge. If a judge, who has shortcomings in his/her job, pretends to the position, the presiding judge can insist that they do not indicate low qualification of the applicant and are not an obstacle to his/her appointment.

It is difficult to overestimate the role of profile prepared by the presiding judge; it is the starting point for deciding on the issue of his/her appointment. Thus, the former deputy chairman of the Arbitration Court of the Astrakhan Region, Sergey Spiridonov, appeared to be in a dubious situation. In the spring of 2012, when deciding on the improvement of the qualification class, he received a profile from the presiding 
judge Aleksandr Egorov stating that Spiridonov "carefully" prepares the processes, "is attentive and objective," professionally and competently organizes the activities of his collegium at the proper level. However, already in December of the same year, when the indicated judge submitted documents together with Egorov for the post of the presiding judge of the Arbitration Court, his profile was changed significantly: "In the presence of complex cases and cases with a wide public resonance, [Spiridonov] went on sick leave, avoiding responsibility, being afraid of making serious decision". According to Egorov, Spiridonov was not respected in the team. [2] And, unfortunately, these is not an isolated case. Of course, profile of the presiding judge does not preclude the appointment of the corresponding candidate for the post of judge; however, his opinion is reputable and, as the materials of the cases examined show, is almost always taken into account by the qualification collegium.

In addition, in accordance with clause 10 of Art. 5 of the Federal Law "On the Status of Judges in the Russian Federation", the presiding judge has the right to disagree with the decision of the
14 qualification collegium of judges on the candidate recommendation for the position of judge. Such disagreement is an obstacle to the appointment and requires adoption of a second decision by the qualification collegium of judges, in which two-thirds of the collegium members shall vote for the appointment of the respective candidate. Moreover, it should be noted that the presiding judges exercised this right 53 times for the period from 2012-2016. [3] Some scientists see in this state of affairs a violation of the principle of the independence of judges, because these provisions of the law allow the presiding judges forming a team "convenient" for the management from the very beginning.

It should be noted that from September 1, 2019, this provision of the law will be amended and the presiding judges will be deprived of the right to disagree with the decision of the qualification collegium of judges.

2) Distribution of cases among judges. From September 1, 2019, the existing legislation is amended. According to these amendments, the automated information system will become the main form of distribution of 
cases between judges and the court composition will be formed in a different order only if it is impossible to use it. When forming the composition of the court, the new system will take into account the work schedule of judges of the judicial compositions, the workload reduction ratio, the complexity of cases, as well as the number of cases in the proceedings of each judge. At the same time, it is obvious that it is difficult to "separate" the presiding judge from the distribution of cases, since there may be cases of a sudden illness of someone judge, his/her withdrawal or selfrejection, when manual distribution of cases is necessary.

According to the general idea of the amendments introduced, no one will be able to make the case to be transferred to a specific judge. However, the introduced system is also not without a human face. As long as there is a possibility of manual intervention, it continues to remain open. Thus, there are precedents when the employees of the court apparatus transferred the case to the "right" hands in the mass media. For example, there are cases of real prosecution of judges for such interference in the distribution of cases in Ukraine [4]. The practicing lawyers note that despite the numerous composition of the judges, the cases are often transferred to the same ones, which indicates that there are certain system settings that allow this state of affairs. [5]

Moreover, the process participants try to circumvent the system by themselves. By the way, such a mechanism was represented by filing identical claims.

3) Disciplinary responsibility of judges. Despite the fact that the legislative decision to bring a judge to disciplinary liability is an advantage of the qualification collegium, the role of the presiding judge in this matter is very significant, his/her presentation is the reason for the disciplinary proceedings. The ambiguity of practice, when a judicial error is the basis for bringing to justice and characterizes the judge's work as a whole, forcing him/her to measure his/her understanding of the law and justice with the position of the management and the higher court, has long been recognized as vicious and requires a qualitative change. Even foreign sources note in this regard that the Russian judicial system has long 
paralyzed itself. It does not need experienced lawyers, but needs effective employees, who can follow orders. [6]

Long-term scoring of the indicated problem had some of its results. Thus, in accordance with the Federal Law "On Amending the Law of the Russian Federation "On the Status of Judges in the Russian Federation" and the Federal Law "On the Judicial Community in the Russian Federation" No. 243-FZ dated July 29, 2018, the right of the presiding judge to initiate disciplinary proceedings will be excluded, the qualification collegium of judges will consider this issue independently from September 1, 2019.

4) Career growth of a judge. It is clear that work is not limited to an appointment to the corresponding position for a person; the possibility of career growth is a priority of his/her development. This is the satisfaction of his/her personal ambitions and material well-being. The possibility of promoting a judge in the service is related to passing qualification certification of judges. A significant place in this procedure is given to the presiding judges of the respective courts. These persons direct the idea of conducting qualification certification, possibility of career advancement. Despite the fact that the judge has the right to independently apply to the appropriate collegium of judges with a statement on the conduct of his/her qualification certification, in any case, the qualification collegium asks the necessary documents from the presiding jedge, including profile, containing an assessment of the judge's professional activities, business and moral qualities.

In addition, it establishes the right of the presiding judge to participate in a meeting of the qualification collegium of judges, which, of course, may expresses his/her reputable opinion about some fears of awarding the appropriate qualification class to a particular judge just in case.

An analysis of the current legislation showed that in addition to regulating the terms during which appropriate certification shall be carried out, there are no other provisions governing the criteria for evaluating the activities of judges. The above makes subjective discretion possible when considering the relevant candidate, all the more so as the results of judicial 
activity and the moral qualities of a judge are subject to evaluation.

5) Encouragement of judges (allowances and bonuses, financial assistance). A significant part of the judge's salary is made up of bonuses and allowances, which can be removed by the decision of the presiding judge in some cases.

When awarding judges based on their work results for a certain period, a number of criteria are taken into account, some of which are blurred and are often interpreted by the presiding judge as convenient. One can fit anything he/she want, promoting or pushing away the respective applicant, under such indicators as "fulfillment of particularly important and complex tasks" or "introduction of progressive forms of judicial activity", "quality of work performed".

6) organizational issues vacation schedule, technical equipment of the workplace, number and qualification of assistant judges, regularity and level of professional development. Another way to influence the activities of judges is the ability of the presiding judge to influence a significant number of issues related to the organization of the activities of judges. There are no documents clearly indicating the boundaries of such actions by the presiding judges. This state of affairs makes it possible for a "disagreeable" judge to work with enormous load on complex cases without an assistant and regular training, when another one will consider cases of little complexity in the best working conditions and with qualified personnel. Of course, we understand that it is very difficult to regulate the indicated activity of the presiding judges, since these issues directly constitute the organizational powers of the presiding judge. We only note that there are often cases of complaints about the unequal attitude of the presiding judge to the judges in the practice of the qualification collegiums of judges. Thus, in one case, the basis for initiating proceedings on bringing a judge to disciplinary liability was the appeal of the presiding judge on untimely execution and presentation of the protocol of the court session. The analysis of indicators of the quality of judicial work, judicial load of this judge in comparison with other judges of this court, showed that the delay in drawing up the protocol of the court session was 
associated with the excessive workload of this judge. There were 34.5 cases per month in his consideration, against the average monthly load of other judges of this court in the amount of 20.9 cases. Over the 14 years of service, he has never received a class promotion and he had the lowest class rank. [7; 138]

In our opinion, the problems of independence of judges arising in connection with the interaction of the latter with the presiding judges of the respective courts can be divided into two types, the content of which dictates the methods of their settlement: 1) problems that have arisen in view of the provision of "excessive" powers to the presiding judges; 2) problems, the legislative regulation of which is difficult or impractical in view of the fact that dependence relations of judges are mediated by the personality of the presiding judge: his/her moral and business qualities.

The first of these types of problems is easily resolved at the legislative level. Part of this work has already been done. The presiding judges are deprived of the right to disagree with the decision of the qualification collegium of judges when appointing a judge, the right to appeal for early termination of the judge's powers in connection with a disciplinary offense, the possibility of checking the materials of appeal in connection with the disciplinary case considered by the qualification collegium. It is established a rule for the automated distribution of cases between judges. However, it is also necessary to resolve the following issues at the legislative level: 1) on the certification procedure of judges with specific criteria for evaluating the work and responsibility of presiding jecges for the late initiation of such certification and the provision of false information; 2) the right of the presiding judge to participate in the meeting of the relevant collegium on the issue of awarding the qualification class to judges shall be excluded; 3) development of clear criteria for evaluating the activities of judges to ensure transparency in the distribution of incentive payments by the judicial department, without participation of the presiding judge.

As for resolving the second type of problem, the situation here is much more complicated, since it arises not so much in connection with the lack of legislative regulation, but in view of the 
depravity of the presiding judge selection system, when a person with dubious moral qualities, who pursues other interests besides ensuring fair justice and normal organization of the court, gets to the top of the tree.

\section{Conclusions}

Personality in history is a philosophical category, but as part of our issue consideration, the role of personality of the presiding judge is generally obvious for the stability of the judiciary system. The central idea of improving legislation shall be represented by provision of the appointment of "worthy" person to the position of the presiding judge. Thus, the whole set of problems of the second kind will be automatically resolved. Now these problems are as follows: providing an objective profile of the presiding judge when deciding on the appointment of a judge and lowering or upgrading his/her qualification class, fair distribution or redistribution of cases between judges in the presence of normal economic and organizational support for the judges. The appointment procedure of the presiding judge is not transparent. The law is limited to indicating the most general requirements for the candidates for judges, but not for the presiding judges. This raises a number of questions, since it is obvious that the provision of additional powers objectively requires the presence of additional requirements, the list of which shall be legally defined and specific. In addition, we discuss the term of office of the presiding judges in the literature. Today, presiding judges are elected for a six-year term, if there is a positive opinion of the respective qualification collegiums of judges of the subjects of the Russian Federation, and the same person can be appointed no more than two times in a row to the indicated position in the same court. In our opinion, the issue of the term of office of the presiding judge is secondary, another issue of reappointment is more significant.

\section{Summary}

The procedure for the reelection of judges in itself and the current mechanism for such re-election, led by the President of the Russian Federation, or rather his apparatus, is the lever on the part of the current government that impedes the development of 
independence of the judiciary system. It should be noted that back in 2014, the report of the mission of the international commission of lawyers noted that the selection and appointment system for judges lacks transparency, strict selection criteria and rules, and accountability, which inevitably leads to arbitrariness and abuse [8]. In fact, the term for which the presiding judge is appointed (especially if this person is worthy) is not so important; it is important what he/she thinks and what he/she shall take into account in order to stay at this place. The irremovability of judges and presiding judges, in particular, without limiting their term of office, provided that a high-quality, effective, and most importantly transparent system for evaluating their work is developed, with a clear establishment of the level and procedure for holding them accountable, up to and including the possibility of depriving them of their respective posts or status, is the most short way to ensuring the independence of the judiciary system in the Russian Federation. The principle of independence of the judiciary system shall be based on the principle of fair and impartial court, and not politics, ideology or special interest [9], which is difficult to exclude in view of the existing reassignment system. We affirm once again that the judicial system in the Russian Federation suffers from the power centralization process [10;190], which was also found within the framework of this study.

\section{Acknowledgements}

The work is performed according to the Russian Government Program of Competitive Growth of Kazan Federal University.

\section{References}

The Russian Constitution and the Specialization of Judges and Courts: The Current Reforms of the Judiciary in Russia. The Celebration of the Russian Judicial Reforms of 1864 [Electronic resource]. - Access mode: https://siberiaforum.utmn.ru/upload/me dialibrary/c60/Marochkin-

Permiakov_RCEEL\%2039_FINAL.pdf - (access date: 10.06.2019)

Characteristics that spoil the career of judges [Electronic resource]. - Access 
mode: $\quad$ https://legal.report/oruzhievlastnyh-sudej/, free - (access date: 10.06.2019)

Struggle for the purity of the ranks: highprofile appointments and resignations of judges [Electronic resource]. - Access mode:

https://pravo.ru/review/view/146556/, free - (access date: 10.06.2019)

The judge was sentenced 5 years of imprisonment for breaking the case distribution system. [Electronic resource]. - Access mode: https://zib.com.ua/ru/10182-

za_vmeshatelstvo_v_avtomatizirovannu yu_sistemu_raspredeleniy.html, free (access date: 10.06.2019)

By the end of the year, the SAC is going to completely exempt court leaders from the distribution of cases [Electronic resource]. - Access mode: https://pravo.ru/review/view/87146/, free - (access date: 10.06.2019)

The Problem With the Russian Judiciary [Electronic resource]. - Access mode: https://carnegie.ru/commentary/75316, free - (access date: 10.06.2019)
Fedorov S.V., Gushchina N.A. Problems of legal regulation of the disciplinary responsibility of judges and the mechanism for their protection in the Russian Federation // Modern Law. 2012. No. 1, P. 135-142.

Appointing the judges: procedures for selection of judges in the Russian Federation IcJ Mission Report 2014 [Electronic resource]. - Access mode: https://www.icj.org/wpcontent/uploads/2014/11/RUSSIASelecting-the-judges-PublicationsReports-2014-Eng.pdf, free - (access date: 2.06.2019)

Preserving a Fair, Impartial and Independent Judiciary [Electronic resource]. - Access mode: http://www.judges.org/wpcontent/uploads/ABOTAJudicialWhitePaper-final.pdf, free (access date: 02.06.2019)

Gubaidullina, E., \& Gubaidullin, A. (2018). Hindering the Development of the Jury Trail in Russian Federation and the Problems of Court Independence. Journal of History Culture and Art Research, 7(4), 185-191 